\title{
Analisis User Experience Webhalal Batam Di Pusat Kajian Halal Politeknik Negeri Batam Menggunakan User Experience Questionaire (UEQ)
}

\author{
Dimas Surya Fitriansyah ${ }^{1}$, Riwinoto ${ }^{2}$ \\ Teknik Informatika, Politeknik Negeri Batam \\ Multimedia dan Jaringan Politeknik negeri Batam
}

\begin{tabular}{l} 
Article Info \\
\hline Article history: \\
Received Des $21^{\text {th }}, 2021$ \\
Revised Des $27^{\text {th }}, 2021$ \\
Accepted Des $28^{\text {th }}, 2021$ \\
\hline
\end{tabular}

Keyword:

$W e b$

User Experience

Pusat Kajian Halal

User Experience Questionaire

\begin{abstract}
Web adalah teknologi saat ini yang dikembangkan dalam berbagai bidang salah satunya dalam bidang pariwisata, namun di dunia pariwisata masih belum terlalu banyak digunakan. Web Halal Batam, merupakan salah satu contoh penggunaan teknologi web di bidang pariwisata halal di kota Batam. Keterbatasan menggunakan brosur sebagai media promosi atau informasi menjadikan web sebagai salah satu media promosi dan informasi yang baik untuk digunkan saat ini. Dalam penelitian ini menggunakan metode User Experience Questionaire untuk melakukan analisis terhadap pengalaman pengguna aplikasi Web Halal Batam terhadap masyarakat atau wisatawan kota Batam yang nantinya akan menghasilkan berupa data terkait tingkat kualitas User Experience pengguna terhadap aplikasi Web Halal Batam. Hasil dari pengukuran User Experience Aplikasi Web Halal Batam mendapatkan hasil yang diatas rata-rata pada parameter attractiveness (1.43), perspicuity (1.54), dependability (1.36), dan novelty (1.08, sedangkan aspek efficiency (1.53) dan stimulation (1.41) berada di katagori baik.
\end{abstract}

\section{Corresponding Author:}

First Author,

Program Studi Multimedia dan Jaringan, Teknik Informatika

Politeknik Negeri Batam,

Batam Centre, Jl. Ahmad Yani, Tlk.Tering, Kec. Batam Kota, Kota Batam, Kepulauan Riau 29461.

Email: iamdimsur@gmail.com

\section{PENDAHULUAN}

Perkembangan komputasi pada awal 1990-an dan internet, teknologi informasi telah menyebar luas di luar konteks tempat kerja dan dapat diterapkan di waktu luang [1], ritel dan pemasaran elektronik [2] dan konsumsi media. Faktor pengalaman seperti estetika dan kenikmatan sudah mulai diterima dan mulai mendapat perhatian dalam Human Computer Interaction (HCI) [3].

Web adalah perangkat lunak yang terdiri dari konvensi, melalui teknik hypertext dan multimedia. web juga memudahkan siapa saja untuk menelusuri dan berkontribusi pada sesuatu [4].

Web telah digunakan di banyak bidang, ada banyak web yang dapat membantu pekerjaan dan membantu mencari informasi. Sudah banyak informasi di web yang bisa membantu dalam banyak hal, seperti membaca tren di pasar, apa saja produk terbaru, layanan yang ditawarkan dan masih banyak lagi, semuanya bisa dilakukan tanpa harus beranjak dari kursi [5].

Dengan kemajuan teknologi informasi seperti sekarang, perkembangan dan promosi pariwisata terlihat semakin nyata. Penggunaan website sebagai alat untuk mempromosikan pariwisata semakin banyak digunakan [6].

Pusat Kajian Halal merupakan salah satu Lembaga yang bernaung di bawah Politeknik Negeri Batam seksi Pusat Penelitian dan Pengabdian kepada masyarakat. Pusat Studi Halal juga merupakan salah satu wujud nyata dari Tridarma Perguruan Tinggi Politeknik Negeri Batam, melalui Pusat Kajian Halal Polibatam nantinya akan menjadi susat kajian atau studi, dan penelitian halal, sosialisasi dan konsultasi proses dan produk halal, serta rencana dari pendirian Lembaga Pemeriksaan Halal (LPH) yang akan berperan dalam proses 
pengelolaan produk halal di Batam, Pusat Kajian Halal juga menjalin kerjasama dengan berbagai lembaga seperti LPPOM MUI dan Badan Penyelenggara Jaminan Produk Halal ( BPJPH) [7].

Pusat Kajian Halal Polibatam sedang mengembangkan web yang menampilkan peta atau peta lokasi restoran dan masjid bersertifikat halal di kota Batam, tujuan dari pembuatan web ini adalah sebagai media informasi kepada wisatawan yang datang ke kota Batam dan carilah restoran yang memiliki sertifikat halal, karena halal itu penting bagi umat muslim.

Keberhasilan sebuah web dilihat dari kualitas web yang memiliki struktur yang baik serta desain yang menarik penting dalam meningkatkan keinginan pengunjung dalam membeli produk dan jasa yang memberikan informasi yang dibutuhkan. Kualitas web perlu dievaluasi dengan harapan web yang dibangun memiliki kualitas yang baik agar banyak pengguna yang mengakses web tersebut, User Interface memiliki peran sebagai penghubung antara pengguna dengan user experience yang diperoleh user. User Interface merupakan mekanisme penerimaan informasi dari pengguna dan kembali ke pengguna untuk membantu mengarahkan alur penelusuran masalah hingga mendapatkan hasil penyelesaiannya [8].

Keberhasilan web tentu tidak bisa dilepaskan dari peran user interface dan user experience. Antara antarmuka pengguna dan pengalaman pengguna memiliki hubungan yang saling bergantung. Antarmuka pengguna merupakan bagian dari sistem yang dapat dilihat, didengar, dan dirasakan [9]. Sedangkan User Experience adalah pengalaman yang diciptakan oleh produk kepada penggunanya di dunia nyata. Hasil kerjasama tersebut membentuk UI/UX yang kemudian akan membangun pengalaman lengkap pengguna web halal batam. Desain apa yang muncul dan bagaimana pengguna merespon juga akan mempengaruhi tindakan yang akan dilakukan oleh pengguna.

Oleh karena itu penulis membuat penelitian yaitu "Analisis User Experience Web Halal Batam Pada Halal Center Polibatam Menggunakan User Experience Questionaire (UEQ)”.

\section{Landasan Teori}

\subsection{Web}

Web adalah sekumpulan halaman yang digunakan untuk menampilkan informasi teks, gambar diam atau bergerak, animasi, suara, dan atau kombinasi dari semuanya yang membentuk rangkaian bangunan yang saling berhubungan yang terhubung ke jaringan halaman. Secara konseptual web adalah klien atau server manajemen database [13].

\subsection{Web Halal Batam}

Web Halal Batam adalah aplikasi berbasis web yang berisi informasi tentang restoran dan masjid bersertifikat halal di kota Batam sebagai panduan bagi masyarakat dan wisatawan muslim yang berkunjung ke kota Batam. Web ini dikembangkan oleh Pusat Kajian Halal Politeknik Negeri Batam sebagai pengabdian kepada masyarakat.

Pada Halal Web Batam terdapat beberapa fitur seperti menyediakan lokasi, kontak pihak restoran agar pembeli dapat menghubungi melalui telepon atau langsung datang ke restoran sesuai dengan alamat yang sudah tertera pada Halal Web Batam, dan juga terdapat dua fitur login yaitu untuk menjadi admin dan pengguna terdaftar, admin memiliki hak khusus seperti mengisi, mengubah, dan menghapus data. Ada juga fitur blog yang akan pindah ke web Pusat Kajian Halal Polibatam yang berisi berita, acara, dan juga tata cara pengurusan sertifikat halal. Pengunjung juga bisa melihat seluruh daftar rumah makan yang datanya sudah terdaftar di halal web batam dan juga masjid-masjid yang ada di kota batam. Berikut tampilan dan fitur Halal Web Batam.

A) Home Page atau Maps pada Web Halal Batam

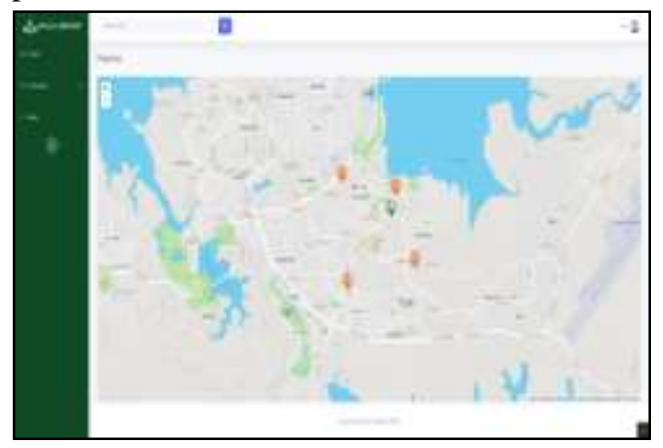

Gambar 1 Halaman Home atau Maps 
B) Halaman Restoran, Masjid

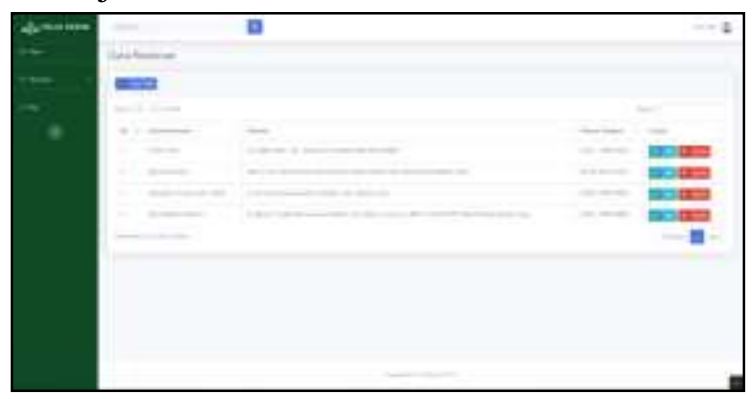

Gambar 2 Halaman data Restoran

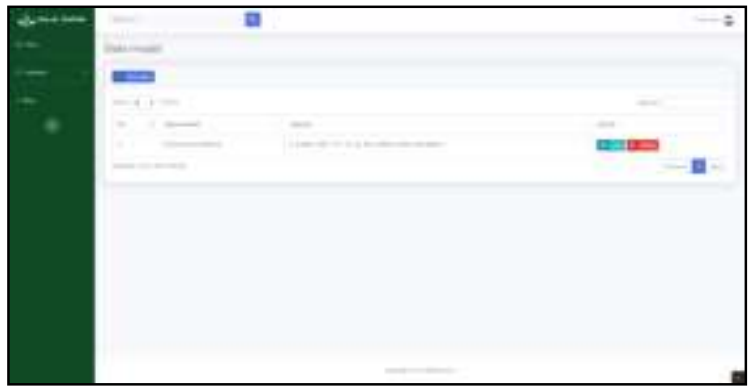

Gambar 3 Halaman data Masjid

C) Halaman Blog

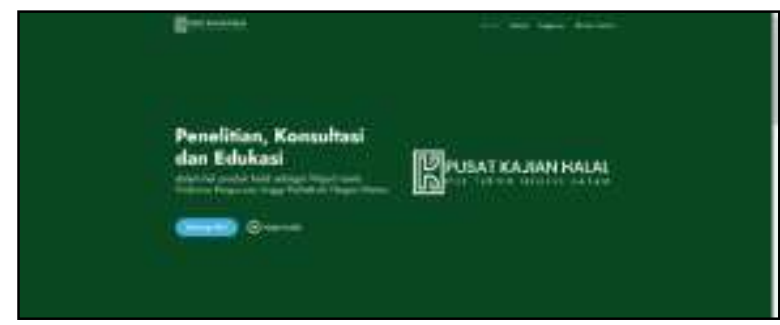

Gambar 4 Halaman Blog

\subsection{Halal}

Kata halal diambil dari bahasa Arab עل yang memiliki arti “diperbolehkan”. Sedangkan pengertian makanan dan minuman halal adalah makanan dan minuman yang boleh dikonsumsi oleh seorang beragama muslim. Selain itu istilah halal, ada juga istilah toyyiban yang memiliki arti "baik" yang dalam pengertian memiliki mutu yang baik serta tidak merusak kesehatan. Dan kita sebagai umat muslim, diwajibkan hanya mengkonsumsi makanan dan minuman halal dan toyyiban (QS 2:168) [14].

\subsection{Makanan Halal}

Dalam ajaran Islam, semua jenis makanan dan minuman pada dasarnya halal, kecuali beberapa yang dilarang. Hal ini sah bagi Anda untuk melakukannya dalam keadaan darurat. Sebaliknya, halal juga bisa haram jika dikonsumsi di luar batas. Yang dimaksud dengan makanan dan minuman halal meliputi:

1. Halal secara zatnya

Hampir semua jenis makanan halal dan bisa dikonsumsi. Kebaikan larangan itu jelas untuk kemaslahatan dan kebaikan umat manusia. Antara lain, sebagai penguji ketaatannya secara rohani melalui makanan dan minumannya dan agar manusia mengetahui atau mau bersyukur.

2. Halal secara proses

Makanan halal tapi jika diolah dengan cara yang tidak halal maka menjadi haram.

3. Halal cara memperolehnya

Islam memberikan tuntunan agar umat muslim hanya makan dan minum yang halal dan thoyyib, artinya makanan yang sehat bagi jasmani dan rohani dan higienis. Mengkonsumsi makanan yang 
diperoleh dengan cara yang tidak baik berarti tidak halal secara spiritual akan berdampak buruk bagi kehidupan spiritual seseorang.

4. Minuman yang tidak halal

Semua jenis minuman yang menyebabkan mabuk adalah haram. Termasuk minuman yang terkontaminasi oleh zat yang dapat memabukkan atau zat yang tidak halal..

\subsection{Pusat Kajian Halal Politeknik Negeri Batam}

Pusat Kajian Halal merupakan salah satu Lembaga yang bernaung di bawah Politeknik Negeri Batam seksi Pusat Penelitian dan Pengabdian kepada Masyarakat. Pusat Studi Halal juga merupakan salah satu wujud nyata dari Tridarma Perguruan Tinggi Politeknik Negeri Batam, melalui Pusat Studi Halal nantinya akan menjadi pusat kajian, kajian dan penelitian kehalalan, sosialisasi dan konsultasi proses dan produk halal, serta rencana pendirian Lembaga Pemeriksaan Halal (LPH) yang akan berperan dalam proses pengelolaan produk halal di Batam, Pusat Kajian Halal juga menjalin kerjasama dengan berbagai lembaga seperti LPPOM MUI dan Badan Penyelenggara Jaminan Produk Halal (LPH). BPJPH).

\subsection{User Experience}

Pengalaman Pengguna adalah persepsi dan tanggapan pengguna sebagai reaksi atas penggunaan suatu produk, sistem, atau layanan (ISO 9241-11). Jadi pengalaman pengguna adalah apa yang dirasakan pengguna saat menggunakan suatu produk.

\subsection{User Experience Questionaire}

Pengalaman Pengguna adalah persepsi dan tanggapan pengguna sebagai reaksi atas penggunaan suatu produk, sistem, atau layanan (ISO 9241-11). Jadi pengalaman pengguna adalah apa yang dirasakan pengguna saat menggunakan suatu produk [15].

User Experience Qustionnaire (UEQ) terdiri dari 6 (enam) skala yaitu: Attractiveness, Perspicuity, Efficiency, Stimulation, Novelty, Dari 6 (enam) skala terdapat 26 item UEQ.

\subsection{UEQ Data Analytic Tools}

Alat analisis data UEQ dapat digunakan untuk memproses data dari kuesioner UEQ. Untuk mengetahui arti dari nilai yang dihasilkan oleh skala UEQ dapat dilakukan dengan membandingkan perhitungan masing-masing skala dengan nilai yang terdapat pada Tabel 1 [16].

Tabel 1 Benchmark Interval Skala UEQ

\begin{tabular}{|c|c|c|c|c|c|c|}
\hline & $\begin{array}{c}\text { Daya Tarik } \\
\text { (attractiveness) }\end{array}$ & $\begin{array}{c}\text { Kejelasan } \\
\text { (perspicuity) }\end{array}$ & $\begin{array}{c}\text { Efisiensi } \\
\text { (efficiency) }\end{array}$ & $\begin{array}{c}\text { Ketepatan } \\
\text { (dependability) }\end{array}$ & $\begin{array}{c}\text { Stimulasi } \\
\text { (stimulation) }\end{array}$ & $\begin{array}{c}\text { Kebaruan } \\
\text { (novelty) }\end{array}$ \\
\hline Excellent & $\geq 1,75$ & $\geq 1,9$ & $\geq 1,78$ & $\geq 1,65$ & $\geq 1,55$ & $\geq 1,4$ \\
\hline Good & $\geq 1,52$ & $\geq 1,56$ & $\geq 1,47$ & $\geq 1,48$ & $\geq 1,31$ & $\geq 1,05$ \\
& $<1,75$ & $<1,9$ & $<1,78$ & $<1,65$ & $<1,55$ & $<1,4$ \\
\hline Above & $\geq 1,17$ & $\geq 1,08$ & $\geq 0,98$ & $\geq 1,14$ & $\geq 0,99$ & $\geq 0,71$ \\
Average & $<1,52$ & $<1,56$ & $<1,47$ & $<1,48$ & $<1,31$ & $<1,05$ \\
\hline Below & $\geq 0,7$ & $\geq 0,64$ & $\geq 0,54$ & $\geq 0,78$ & $\geq 0,5$ & $\geq 0,3$ \\
Average & $<1,17$ & $<1,08$ & $<0,98$ & $<1,14$ & $<0,99$ & $<0,71$ \\
\hline Bad & $<0,7$ & $<0,64$ & $<0,54$ & $<0,78$ & $<0,5$ & $<0,3$ \\
\hline
\end{tabular}

\subsection{Uji Instrument Alfa Cronbach}

Pengujian reliabilitas menggunakan Alpha Cronbach test dilakukan untuk lebih dari satu jawaban benar dan instrument berbentuk angket. Rumus koefisien realibilitas adalah sebagai berikut.

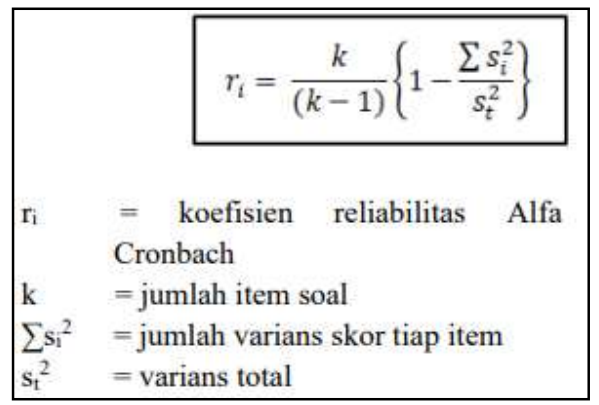


Gambar 7 Alpha Cronbach Formula

Jika koefisien reliabilitas Alpha Cronbach telah dihitung (ri), kemudian dibandingkan dengan kriteria koefisien reliabilitas Alpha Cronbach untuk instrument yang reliabel. menurut Nunnally (dalam Streiner, 2003) menyatakan bahwa instrument dinyatakan reliabel jika koefisien reliabilitas Alpha Cronbach lebih dari 0,70 (ri > 0,70) dan Streiner sendiri (2003) menyatakan bahwa koefisien reliabilitas Alpha Cronbach, seharusnya tidak lebih dari 0,90 (ri < 0,9).

Jika koefisien reliabilitas Alpha Cronbach kurang dari 0,70 (ri < 0,70), Tavakol \& Dennick (2011) menyarankan untuk melkukan perubahan atau menghilangkan item pertanyaan yang memiliki korelasi rendah dan disarankan untuk mengurangi jumlah pertanyaan dengan kriteria pertanyaan yang sama meskipun dalam kalimat yang berbeda [17].

\section{METODE PENELITIAN}

\subsection{Metode Penelitian}

Metode penelitian yang digunakan dalam penelitian ini adalah pengujian user experience menggunakan User Experience Questionnaire. User experience adalah persepsi dan respon pengguna sebagai reaksi penggunaan sebuah produk, sistem, maupun layanan [10]. Gambar 5 merupakan Tahapan Penelitian.

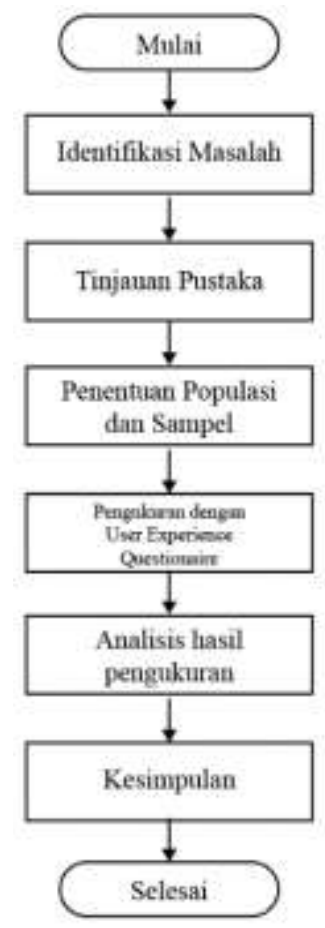

Gambar 5 Tahapan Penelitian

Langkah awal yang dilakukan untuk mengidentifikasi masalah yang akan dianalisis oleh penulis dalam melakukan analisa User Experience terhadap Web Halal Batam menggunakan User Experience Questionaire untuk mendapatkan hasil data evaluasi pada Web Halal Batam. Karena belum adanya data pengalaman pengguna yang menguji Web Halal Batam sebagai media informasi yang kedepannya menjadi saran perbaikan terhadap Web Halal Batam di kemudian hari.

Proses tinjauan pustaka dilakukan agar penulis mendapat referensi berupa jurnal atau artikel yang berkaitan dengan analisis User Experience suatu web menggunakan User Experience Questionaire dan mendapat kan hasil untuk evaluasi terhadap Halal batam.

Populasi pada penelitian ini merupakan masyarakat umum yang beragama muslim dan minimal satu kali dalam seminggu makan di restoran. Sampel yang digunakan dalam penelitian ini adalah sebanyak 110 orang. Penelitian ini menggunakan Teknik random sampling dikarenakan tidak 
memperhatikan strata yang ada didalam populasi itu dan populasi dianggap homogen [11]. Populasi yang digunakan adalah masyarakat beragama muslim.

Penelitian membutuhkan kuisioner yang akan dibagikan kepada sampel, dalam kuisioner tersebut terdapat 26 buah pertanyaan yang disertai dengan jawaban dari rentang 1-7. Produk akhir akan diberikan kepada sampel untuk memastikan bahwa media informasi ini sesuai dapat dipahami dan digunakan. Pengujian akan dilakukan oleh masyarakat dengan memberikan kuisioner online untuk mengetahui User Experience pada Web Halal Batam. Berikut ini merupakan contoh kuisioner UEQ.

Penelitian membutuhkan kuisioner yang akan dibagikan kepada sampel, dalam kuisioner tersebut terdapat 26 buah pertanyaan yang disertai dengan jawaban dari rentang 1-7. Produk akhir akan diberikan kepada sampel untuk memastikan bahwa media informasi ini sesuai dapat dipahami dan digunakan. Pengujian akan dilakukan oleh masyarakat dengan memberikan kuisioner online untuk mengetahui User Experience pada Web Halal Batam. Berikut ini merupakan contoh kuisioner UEQ [12].

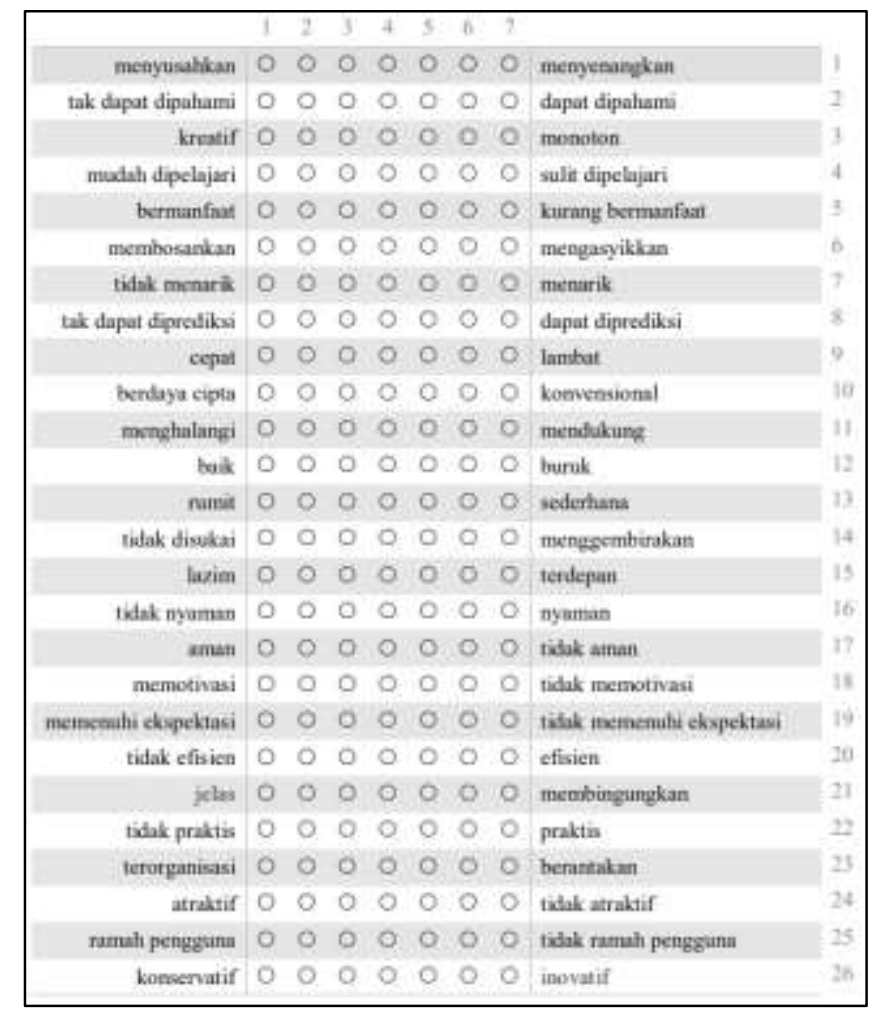

Gambar 6 Contoh Kuisioner UEQ

\section{HASIL DAN ANALISIS}

\subsection{Hasil Analisa UEQ}

Tingkat user experience pada Aplikasi Web Halal Batam yang pengujiaanya dilakukan dengan menggunakan metode UEQ berupa kuesioner dengan 26 pertanyaan tentang analisis produk yang diberikan kepada 110 masyarakat muslim di kota Batam.

Setiap pertanyaan memiliki skala peniliaian 1-7. Data berupa jawaban dari responden dan dimasukkan ke dalam tab "Data" yang mana nilai jawaban masih menunjukan skala penilaian 1 sampai dengan 7. Hasil jawaban kuesioner UEQ dapat dilihat pada Gambar 8. 


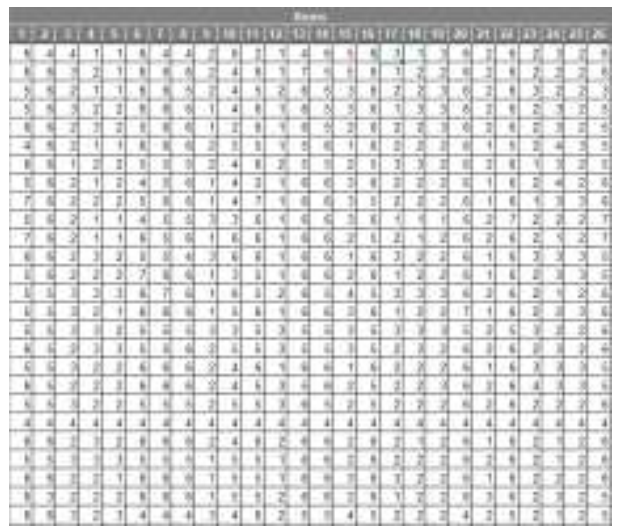

Gambar 7 Hasil Kuisioner UEQ

Setelah mendapatkan hasil jawaban dari responden kemudian dilakukan konversi menjadi bobot nilai dari nilai 1 sampai 7 menjadi skala dari -3 (setuju sepenuhnya dengan nilai negative) hingga +3 (setuju sepenuhnya dengan nilai positif) atau pun sebaliknya. Berikut contoh nilai yang sudah dirubah, dimulai dari istilah negative ke positif yang dapat dilihat pada Tabel 2.

Tabel 2 Transformasi Skala UEQ

\begin{tabular}{|c|c|c|c|c|c|c|c|c|}
\hline Skale prailaian & 1 & 2 & 3 & 4 & 5 & 6 & 7 & \\
\hline Memywahikau & $n$ & $n$ & a & * & " & - & * & Menyenangkail \\
\hline Nitai wetelah inseformasi & 3 & -2 & -1 & 0 & +1 & $\boldsymbol{n} 2$ & +3 & \\
\hline
\end{tabular}

Untuk tranformasi skala nilai yang dimulai dari istilah positif ke negatif dapat dilihat pada Tabel 3.

Tabel 3 Tranformasi Skala UEQ

\begin{tabular}{|c|c|c|c|c|c|c|c|c|}
\hline Skala penilain & 1 & 2 & 3 & 4 & 5 & 6 & 7 & \\
\hline Bermanfaat & 0 & - & 0 & - & 0 & - & 0 & $\begin{array}{c}\text { Kurang } \\
\text { Bermanfaat }\end{array}$ \\
\hline $\begin{array}{c}\text { Nilai setelah } \\
\text { tranformasi }\end{array}$ & +3 & -2 & +1 & 0 & -1 & -2 & -3 & \\
\hline
\end{tabular}

Berikut gambar yang merupakan sebagian hasil tranformasi nilai jawaban dari 110 responden yang dapat dilihat Gambar 9.

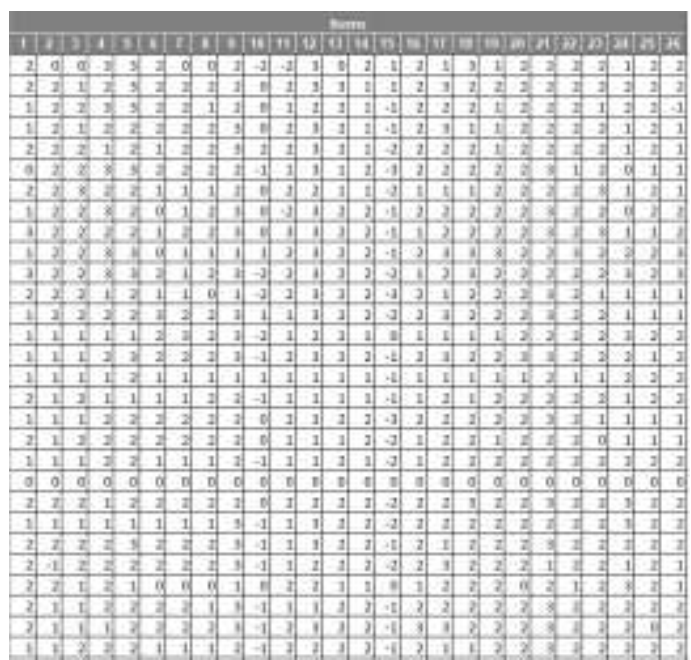

Gambar 8 Hasil Tranformasi Data Jawaban

Koefisien Alpha Cronbach menjelaskan tentang konsistensi terhadap jawaban untuk semua item pada semua skala. Suatu data analisis menggunakan User Experience Questionnaire (UEQ) dapat dikatakan memiliki konsistensi yang tinggi jika nilai dari koefisien Alpha Cronbach lebih besar atau 
sama dengan 0,7. Hasil koefisien reliabilitas Alpha Cronbach didapat dengan mencari terlebih dahulu nilai korelasi dengan cara menghitung nilai rata-rata setiap pasangan item pada skala.

Pada table 4 berikut menunjukkan bahwa semua skala mendapatkan nilai koefisien Alpha Cronbach yang lebih besar dari 0,7 dengan rincian attractiveness $(0.87)$, perspicuity $(0,80)$, efficiency (0.82), dependability (0.79), stimulation (0.82), dan novelty $(0,70)$. Semua skala memiliki nilai diatas 0.7 berarti jawaban pada setiap item memiliti konsistensi yang baik.

Dilanjutkan dengan mencari nilai rata-rata untuk seluruh hasi lkorelasi pada skala. Lalu mencari nilai Alpha Cronbach dengan cara nilai rata-rata dikali jumlah item per skala. Setelah melakukan konfirmasi terhadap skala inkonsistensi jawaban, kemudian dilakukan perhitungan mean, variance dan simpangan baku pada data jawaban responden.

Tabel 4 Koefisien Rieliabilitas Alpha Cronbach

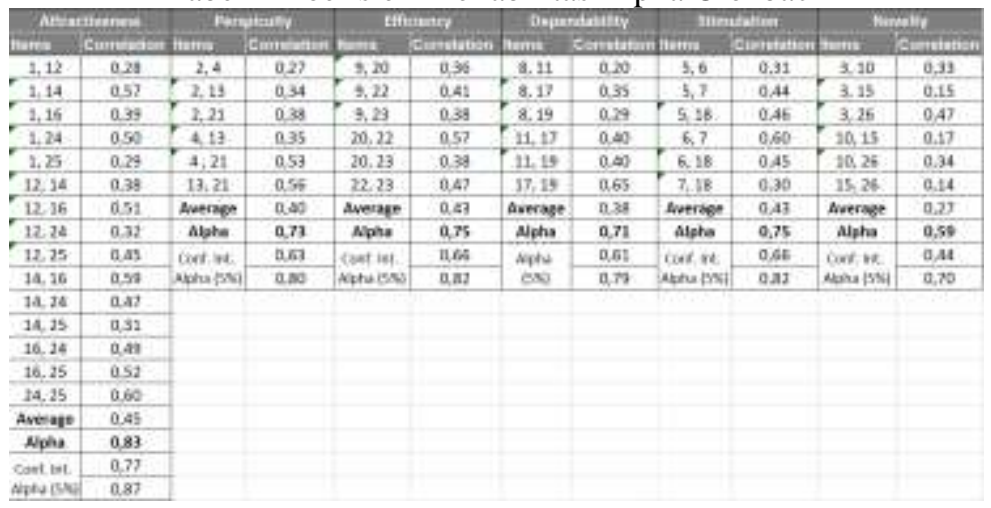

Setelah mendapatkan hasil terhadap skala inkonsistensi jawaban, kemudian dilakukan perhitungan rata-rata, varian dan standart deviasi pada data jawaban responden. Berikut hasil dari perhitungan rata-rata, varian dan standart deviasi dimana masing-masing pertanyaan sudah diberikan kode warna yang berbeda pada setiap skalanya yakni daya tarik, ketepatan, kejelasan, efisiensi, stimulasi dan kebaruan. Hasil rata-rata, varian dan standart deviasi dapat dilihat pada tabel 5 berikut:

Tabel 5 Rata-rata dari hasil Pengukuran UEQ

\begin{tabular}{|c|c|c|c|c|c|c|c|}
\hline Item & Mean. & Variance & Sid, Dew. & Xa. & tent & Riphis & Scale. \\
\hline 1 & $\sqrt{1,3}$ & 0.8 & 0,9 & 110 & annoping & enjoyable & Aftractiveness \\
\hline 2 & 1,5 & 0,8 & 0,9 & 110 & not understandable & understandable & Perspicuty \\
\hline 3 & ㄴ.4. & 0,7 & 0,9 & 110 & croative & dull & Novalty \\
\hline 4 & 1.4 & 1,9 & 1,4 & 110 & easy to learn & difficult to leam & Perspiculy \\
\hline 5 & 1.6 & 1.4 & 1.2 & 110 & valcable & inferior & Stimulation \\
\hline 0 & 1,2 & 1,2 & 1,1 & 110 & boring & exciting & Stimulation \\
\hline 7 & 1,4 & 0.5 & 0,9 & 110 & not interesting & interesting & Stimulation \\
\hline 8 & A 1,4 & 0,8 & 0,9 & 110 & unpredictable & predictable & Dependabubity \\
\hline 9 & 1.7 & 1.3 & 1,1 & 110 & Gst & Slaw & Eficiency \\
\hline 10 & T. 0,9 & 0,7 & 0,9 & 110 & imentive & corsuemional & Novelty \\
\hline 11 & 1,3 & 1,1 & 1,1 & 110 & abstructive & suppertive & Dependability \\
\hline 12 & 1,7 & 1,4 & 1,2 & 110 & good & bad & Attractiveness \\
\hline 13 & 1.7.7 & 0.8 & 0,9 & 110 & complicated & easy & Perspiculty. \\
\hline 14. & 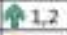 & 0,8 & 0,9 & 110 & unlikabie & pleasing & Attractivenes 65 \\
\hline 15. & 0,7 & 0,6 & 0,8 & 110 & แระa) & leading adge & Nevelty \\
\hline 16 & A 1,4 & 0,7 & 0,9 & 110 & ungloasant & pleasant & Attractiveness \\
\hline 17 & T 1.4 & 1.1 & 1,1 & 110 & secure & not secure & Dependability. \\
\hline 18 & 1., & 0.9 & 1.0 & 110 & motrating & demotwsting & Stimulation \\
\hline 19 & 1,3 & 1,3 & 1,1 & 110 & meets expectations & does not mest expectations & Oependability \\
\hline 20 & 1,6 & 0,7 & 0,8 & 110 & inefficiont & efficient & Extriency \\
\hline 21 & 1.6 & 1,5 & 1,2 & 110 & cleat & confusing & Perspicuty \\
\hline 22 & 1.5 & 0.9 & 0,9 & 110 & impractical & practeal & Efrciency \\
\hline 23 & 1,4 & 1,1 & 1,0 & 110 & arganized & cluttered & Eficiency \\
\hline 24 & 1,3 & 1,3 & 1,1 & 110 & attractive & unattractive & Attractiveness \\
\hline 25 & 1,6 & 1,0 & 1,0 & 110 & fiendly & unfriendly & Attractiveness \\
\hline 26 & A. 1.4 & 0,8 & 0,5 & 110 & conservative & innovative & Novelty \\
\hline
\end{tabular}

Berikut adalah hasil dari nilai rata-rata berdasarkan seluruh pertanyaan yang telah kategorikan kesetiap skala. Nilai rata-rata yang didapatkan - 0.8 dan 0.8 merupakan nilai evaluasi normal, nilai di atas 0,8 merupakan evaluasi positif dan nilai-nilai di bawah -0,8 merupakan evaluasi negatif. Sehingga dapat diambil kesimpulan bahwa aplikasi Web Halal Batam memiliki impresi positif dari setiap skala 
yaitu, Daya tarik, Kejelasan, Efisiensi, Ketepatan, Stimulasi dan Kebaruan yang dapat dilihat pada Tabel 6 dan grafik yang menunjukan skala pada Gambar 10.

Table 6 Hasil Rata Rata Berdasarkan Skala

\begin{tabular}{|l|r|r|}
\hline \multicolumn{3}{|c|}{ UEQ Scales (Mean and Variance) } \\
\hline Attractiveness & 1,426 & 0,53 \\
\hline Perspicuity & 1,543 & 0,67 \\
\hline Efficiency & 1,525 & 0,54 \\
\hline Dependability & 1,361 & 0,59 \\
\hline Stimulation & 1,414 & 0,61 \\
\hline Novelty & 个 1,082 & 0,33 \\
\hline
\end{tabular}

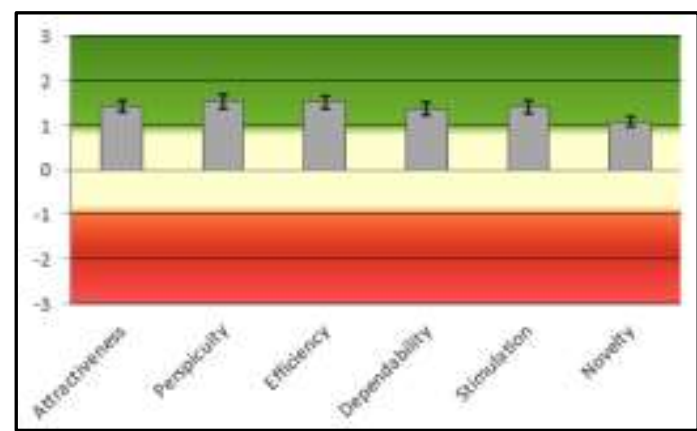

Gambar 9 Grafik Rata-rata Berdasarkan Skala

Hasil perhitungan analisis dapat disajikan berdasarkan tiga kelompok aspek yaitu attractiveness (Daya Tarik) yang merupakan dimensi valensi murni, pragmatic quality (Kualitas pragmatis) yaitu aspek yang menggambarkan kualitas dari interaksi pengguna yang berhubungan dengan tugas ataupun tujuan serta hedonic quality (kualitas hedonis) yaitu gambaran dari aspek yang berkaitan dengan kesenangan saat menggunakan produk. Dimana hasil yang didapatkan evaluasi UEQ untuk aspek attractiveness dengan nilai 1,43 untuk pragmatic quality dengan nilai 1,48. Serta 1,25 untuk hedonic quality. Dapat dilihat pada Tabel 8.

Tabel 8 Hasil mean pada setiap kelompok UEQ

\begin{tabular}{|l|c|}
\hline \multicolumn{2}{|c|}{ Pragmatic and Hedonic Quality } \\
\hline Attractiveness & 1,43 \\
\hline Pragmatic Quality & 1,48 \\
\hline Hedonic Quality & 1,25 \\
\hline
\end{tabular}

Hasil akhir dari kuisioner UEQ dapat dilihat tab "Benchmark” yang dapat dilihat pada Gambar 11.

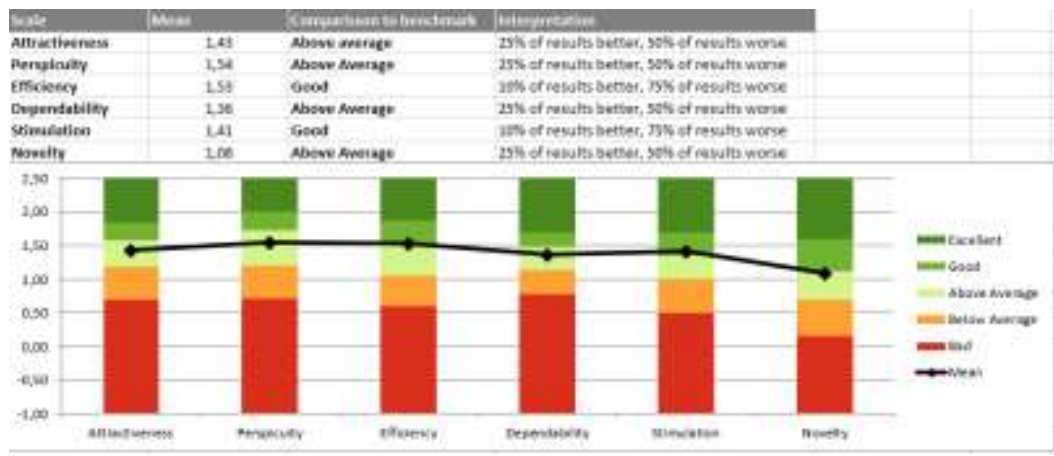

Gambar 10 Benchmark

Berdasarkan pada hasil dari tab "benchmark" dapat dilihat bahwa untuk aspek UEQ yaitu attractiveness (1.43), perspicuity (1.54), dependability (1.36), dan novelty (1.08) berada pada kategori di atas rata-rata, sedangkan aspek efficiency (1.53) dan stimulation (1.41) berada di katagori baik. 


\section{KESIMPULAN}

Hasil dari proses analisis data yang telah dilakukan berdasarkan enam aspek parameter serta rekomendasi untuk penyempurnaan pada aplikasi Web Halal Batam mendapatkan hasil dengan katagori baik dan mendapatkan nilai di atas rata - rata sesuai dengan nilai yang sudah di tetapkan sehingga dapat digunakan sebagai aplikasi yang memberikan informasi restoran makanan bersertifikat halal Batam kepada masyarakat di kota Batam.

Setelah di observasi dari keenam parameter yang digunakan,, 5 kriteria pada Attractiveness, Perspiculty, Dependabillity, Efficiency, Stimulation mengidentifikasi bahwa aplikasi menjadi daya tarik masyarakat mendapat skala penilaian 1,43, Kejelasan dan mudah untuk di pahami mendapat skala penilaian 1,54, Ketepatan dalam menggunakan aplikasi mendapat skala penilaian 1,36, efisien dalam operasinya mendapat skala penilaian 1,53, Memotivasi dan bermanfaat sebagai aplikasi yang memberikan informasi mendapat skala penilaian 1,41. Sedangkan untuk kriteria novelty dengan hasil perbandingan benchmark terendah pada kategori diatas rata-rata dari 5 skala lainnya dengan dengan nilai 1.08, tetapi masih dalam katagori di atas rata - rata dikarenakan pada aplikasi Web Halal Batam masih dalam tahap pengembangan sehingga masih sangat sederhana pada tampilannya, responden mengharapkan adanya inovasi baru atau pun meningkatan tampilan agar mengikuti tren saat ini.

\section{REFERENCES}

[1] Heijden, H., 2004. User Acceptance of Hedonic Informastion System. Management Information Systems Research Center, University of Minnesota, Volume 28, pp. 695-704.

[2] Barwise, P., Elberse, A. \& Hammond, K., 2002. Marketing and Internet. Future Media Research Programme.

[3] Chen, Y.-H. H. \& Corkindale, D., 2008. Towards an understanding of the vehavioral intention to use online news services. internet research, 18(3), pp. 286-312..

[4] Hassenzahl, M. \& Tractinsky, N., 2006. User Experience - a research agenda. Behaviour \& Information Technology, 25(2), pp. $91-97$.

[5] Fáilte Ireland, 2013. Introduction to the Web.

[6] Lengkong, C. M., Sengkey, R. \& Sugiarso, B. A., 2019. Sistem Informasi Pariwisata Berbasis Web di Kabupaten Minahasa. Jurnal Teknik Informatika, 14(1).

[7] Polibatam, "Pusat Kajian Halal (PKH) Politeknik Negeri Batam Gelar Pelatihan Manajemen Keuangan Masjid" 2019. [Online]. Available: https://www.polibatam.ac.id/pusat-kajian-halal-pkh-politeknik-negeri-batam-gelar-pelatihanmanajemen-keuangan-masjid/. [Accessed 17 January 2021].

[8] Griffin, B., dan Baston, L. Interfaces.: Girton Colege University of Cambridge.Cambridge.2014.

[9] Schrepp, M. et al., 2019. Developing a UX KPI based on the User Experience Questionnaire. Computer Standarts \& Interfaces.

[10] Sugiyono, 2015. Metode Penelitian Kuantitatif. Kualitatif dan R\&D. Bandung Alfabeta.

[11] Santoso, H. B. et al., 2016. Measuring User Experience of the Student-Cetered e-Learning Enviroment. The Journal of Educators Online-JEO, 13(1).

[12] Lauesen, S., 2005. User Interface Design: A Software Engineering Perspective. s.1.:Pearson/Addison-Wesley.

[13] W3c, "About the World Wide Web" 2001. [Online]. Available: https://www.w3.org/WWW/. [Accessed 11 Desember 2020].

[14] IHATEC, "Pengertian Makanan dan Minuman Halal" 2021. [Online]. Available: https://ihatec.com/pengertianmakanan-halal/. [Accessed 20 Mei 2021].

[15] Rauschenberger, M., Cota, M. P. \& Thomaschewski, J., 2013. Efficient Measurement of the User Experience of Interactive Products. How to use the User Experience Questionnaire (UEQ).Example: Spanish Language Version. International Journal of Artificial Intelligence and Interactive Multimedia,, 2(1).

[16] Henim, S. R. \& Sari, R. P., 2020. Evaluasi User Experience Sistem Informasi Akademik Mahasiswa pada Perguruan Tinggi Menggunakan User Experience Questionnaire. Jurnal Komputer Terapan, VI(1), pp. 69-78.

[17] Yusup, F., 2018. UJI VALIDITAS DAN RELIABILITAS INSTRUMEN PENELITIAN KUANTITATIF. Jurnal Tarbiyah: Jurnal Ilmiah Kependidikan, VII(1), pp. 17-23. 